\title{
Nitric Oxide Synthase Genotype Modulation of Impulsivity and Ventral Striatal Activity in Adult ADHD Patients and Healthy Comparison Subjects
}

Martine Hoogman, M.Sc.

Esther Aarts, Ph.D.

Marcel Zwiers, Ph.D.

Dorine Slaats-Willemse, Ph.D.

Marlies Naber, BA.Sc.

Marten Onnink, M.Sc.

Roshan Cools, Ph.D.

Cornelis Kan, Ph.D., M.D.

Jan Buitelaar, Ph.D., M.D.

Barbara Franke, Ph.D.

\begin{abstract}
Objective: Attention deficit hyperactivity disorder (ADHD) is a highly heritable disorder. The NOS1 gene encoding nitric oxide synthase is a candidate gene for ADHD and has been previously linked with impulsivity. In the present study, the authors investigated the effect of a functional variable number of tandem repeats (VNTR) polymorphism in NOS1 (NOS1 exon 1f-VNTR) on the processing of rewards, one of the cognitive deficits in ADHD.
\end{abstract}

Method: A sample of 136 participants, consisting of 87 adult ADHD patients and 49 healthy comparison subjects, completed a reward-related impulsivity task. A total of 104 participants also underwent functional magnetic resonance imaging during a reward anticipation task. The effect of the NOS1 exon 1f-VNTR genotype on reward-related impulsivity and reward-related ventral striatal activity was examined.

Results: ADHD patients had higher impulsivity scores and lower ventral striatal activity than healthy comparison subjects. The association between the short allele and increased impulsivity was confirmed. However, independent of disease status, homozygous carriers of the short allele of NOS1, the ADHD risk genotype, demonstrated higher ventral striatal activity than carriers of the other NOS1 VNTR genotypes.

Conclusions: The authors suggest that the NOS1 genotype influences impulsivity and its relation with ADHD is mediated through effects on this behavioral trait. Increased ventral striatal activity related to NOS1 may be compensatory for effects in other brain regions.

(Am J Psychiatry 2011; 168:1099-1106)

(5), as evidenced by steeper temporal discounting rates, altered decision making, and an aversion to delay of gratification in reward-related tests (6-9). Temporal discounting is the patient's preference to receive smaller rewards sooner rather than larger rewards later and is postulated to be an intermediate phenotype for impulsivity. Neuroimaging studies have shown engagement of alternative brain regions in decision making in ADHD patients (10). A prominent feature is hypoactivation of the ventral striatum, a brain area with an important role in reward processing $(11,12)$, during reward anticipation $(13,14)$. Ventral striatal activity is also associated with impulsivity, a hallmark of ADHD $(12,13)$.

Recently, the NOS1 gene was identified as a candidate gene for ADHD and other impulsivity disorders (15). A variant in this gene was also among the top findings of a genome-wide association study in ADHD (3). NOS1 encodes nitric oxide synthase 1 . Nitric oxide, the product of this enzyme's activity, acts as the second messenger downstream of the $N$-methyl-D-aspartate receptor and interacts with both the dopaminergic and serotonergic systems in the human brain. Nitric oxide inhibits monoamine transporters, thereby modulating the dopamine and noradrenalin concentration in the extracellular space (16). In addi- 
tion, NOS1 functions in neurite outgrowth, suggesting an early influence on brain development (17).

Located on chromosome 12, the NOS1 gene has a complex structure, consisting of 28 protein coding exons, with 12 alternative untranslated first exons referred to as exons 1a11. In exon 1f, a variable number of tandem repeats (VNTR) polymorphism that alters gene expression is present (15). This exon has a relatively high expression in the brain, with high specificity for the basal ganglia, including the striatum. Since NOS1 modulates tonic extracellular dopamine levels and phasic dopaminergic neuron spike activity, it might affect disorders with deficient striatal functioning (18). Targeted disruption of Nosl in mice increased impulsivity and aggressiveness, reduced anxiety, and impaired learning (19, 20). Human behavioral and imaging studies have shown NOS1 exon 1f-VNTR to be associated with hyperactive, impulsive, and aggressive behavior as well as hypofunctioning of the anterior cingulate cortex $(15,21,22)$.

Although the NOS1 gene has been linked to ADHD, impulsivity, and modification of neurotransmitter levels in the striatum, effects of NOS1 genetic variation on striatal activity have not been investigated. The objective of the present study was to better understand the effect of this gene on neurobiological dysfunctioning in adult ADHD by exploring the influence of the exon If-VNTR on impulsivity and reward-related striatal activity in a large sample of adult ADHD patients $(\mathrm{N}=87)$ and healthy comparison subjects $(\mathrm{N}=49)$. Given the results of previous studies, we expected to find 1) higher impulsivity scores as well as 2) ventral striatal hypoactivation in ADHD patients relative to healthy comparison subjects, 3) increased impulsivity in homozygous carriers of the NOS1 exon lf-VNTR short allele, and 4) modulation of ventral striatal activity by the exon lf-VNTR.

\section{Method}

\section{Participants}

One hundred and 36 individuals (adult ADHD patients, N=87; healthy comparison subjects, $\mathrm{N}=49$ ) from the Dutch cohort of the International Multicenter persistent ADHD CollaboraTion (IMpACT [23]) participated in the present study. All participants underwent endophenotypic tests for adult ADHD in which cognitive functioning and neuroimaging data were collected. The ADHD patients and an age-, gender-, and IQ-comparable group of healthy subjects were recruited from the department of Psychiatry of the Radboud University Nijmegen Medical Centre (Nijmegen, the Netherlands) and through advertisement. Patients were included if they met DSM-IV-TR criteria for ADHD in childhood as well as adulthood. All participants were assessed using the Diagnostic Interview for Adult ADHD (24). This interview focuses on the 18 DSM-IV symptoms of ADHD and uses concrete and realistic examples to thoroughly investigate whether a symptom is currently present or was present in childhood. In order to obtain information about ADHD symptoms and impairment in childhood, additional information was acquired from parent and school reports whenever possible. The Structured Clinical Interview for DSM-IV (SCID-I) was used for comorbidity assessment. Assessments were carried out by trained professionals (psychiatrists or psychologists). In addition, a quantitative measure of clinical symptoms was obtained using the ADHD Rating Scale-IV (25).
Exclusion criteria for participants were psychosis, alcohol or substance addiction in the last 6 months, current major depression (assessed using SCID-I), full-scale IQ estimate $<70$ (assessed using the Wechsler Adult Intelligence Scale-III), neurological disorders, sensorimotor disabilities, non-Caucasian ethnicity, and medication use other than psychostimulants or atomoxetine. An additional exclusion criterion for healthy comparison subjects was a current or past neurological or psychiatric disorder according to SCID-I. Twenty-eight patients were medication-naïve at the time of the trial. Patients who were receiving treatment with ADHD medication (methylphenidate [N=44], atomoxetine [N=4], and dextroamphetamine [ $\mathrm{N}=11]$ ) were asked to withhold use of their medication 24 hours prior to testing. As a result of excessive movement during scanning $(\mathrm{N}=4)$, metal in the body or tattoos $(\mathrm{N}=25)$, and technical problems $(\mathrm{N}=3)$, the final sample size for the imaging part of the study was 104 (ADHD patients, $\mathrm{N}=63$; healthy comparison subjects, $\mathrm{N}=41$ ). This final sample included 19 medication-naïve patients; 26 ADHD patients and 18 comparison subjects in this subsample were men. Participants had to refrain from smoking prior to and during testing (26). Indirect effects of smoking were controlled for by taking smoking habits (yes/no) into account in the analysis. This study was approved by the regional ethics committee. Written informed consent was obtained from all participants.

\section{Genotyping}

Genotyping of the exon 1f-VNTR was performed by sequencelength analysis on a genetic analyzer (see the data supplement accompanying the online version of this article). The resulting genotypes were converted to short (S) and long (L) alleles. The homozygous short allele (short-short [SS]) genotype has been identified as a risk factor for psychiatric disorders (15), and therefore genotypes were stratified into an SS carrier group and a group of participants carrying at least one long allele (short-long [SL]/ long-long [LL]) for the behavioral and functional data analyses.

\section{Behavioral Task: Reward-Related Impulsivity}

The delay discounting task (27) was administered to measure reward-related impulsivity. On each trial of this task, participants had to choose between varying amounts of hypothetical immediate rewards and hypothetical delayed rewards. A total of 110 questions (such as, "Which do you prefer: 30 euro 180 days from now or 2 euro now?”) were displayed on a screen. In successive questions, the amount of immediate money was increased until it equaled the delayed reward. This way, the personal point of indifference, where two options have equal subjective value to an individual, was determined for every participant. Indifference points were determined for three delayed reward conditions $(10,30$, and 100 euros) and five different delays (2, 30, 180, 365, and 730 days). By using a discount function, an impulsivity parameter $(k)$ could be derived. Previous studies have shown that discounting curves fit well with hyperbolic functions (28). The discount function for the task was as follows: $V=a /(1+k D)$. For this equation, " $V$ " represents the present value of the delayed reward, in this case the indifference point, and "a" represents the delayed reward (10, 30, or 100 euro) at delay “ $D$ " $(2,30,180,365$, or 730 days). Higher levels of $k$ correspond to steeper discounting rates and higher levels of impulsivity (29). The main outcome measure was the average $\mathrm{k}$ for 10 euro $\left(k_{10}\right), 30$ euro $\left(k_{30}\right)$, and 100 euro $\left(k_{100}\right)$ and the average score of all trials $\left(k_{\text {all }}\right)$. A logarithmic transformation was performed to normalize $k$ values $(\log k)$.

\section{Functional Magnetic Resonance Imaging (fMRI) Reward Anticipation Paradigm}

To examine neural responses to reward anticipation, participants were scanned while performing a modified monetary incentive delay task, which has been shown to induce ventral 
TABLE 1. Demographic Characteristics of Adult ADHD Patients and Healthy Comparison Subjects Stratified by the NOS1 Genotype $^{\mathrm{a}}$

\begin{tabular}{|c|c|c|c|c|c|c|c|c|}
\hline \multirow{4}{*}{ Characteristic } & \multicolumn{4}{|c|}{ ADHD Patients } & \multicolumn{4}{|c|}{ Comparison Subjects } \\
\hline & \multicolumn{4}{|c|}{ Genotype } & \multicolumn{4}{|c|}{ Genotype } \\
\hline & \multicolumn{2}{|c|}{$\begin{array}{l}\text { SS Allele Carrier } \\
\quad(\mathrm{N}=16)\end{array}$} & \multicolumn{2}{|c|}{$\begin{array}{l}\text { SL/LL Allele Carrier } \\
\qquad(\mathrm{N}=71)\end{array}$} & \multicolumn{2}{|c|}{$\begin{array}{l}\text { SS Allele Carrier } \\
(\mathrm{N}=11)\end{array}$} & \multicolumn{2}{|c|}{$\begin{array}{l}\text { SL/LL Allele Carrier } \\
\qquad(\mathrm{N}=38)\end{array}$} \\
\hline & Mean & SD & Mean & SD & Mean & SD & Mean & SD \\
\hline Age (years) & 39.4 & 11.0 & 37.1 & 11.6 & 38.5 & 11.3 & 37.5 & 11.0 \\
\hline $1 Q^{b}$ & 10.4 & 1.9 & 11.1 & 2.6 & 12.3 & 1.5 & 11.4 & 2.9 \\
\hline Inattentive symptoms & 6.6 & 1.8 & 6.2 & 2.1 & 1.4 & 1.0 & 0.5 & 0.8 \\
\hline \multirow[t]{2}{*}{ Hyperactive/impulsive symptoms } & 5.9 & 1.7 & 5.4 & 2.2 & 1.0 & 2.4 & 0.7 & 1.0 \\
\hline & $\mathrm{N}$ & $\%$ & $\mathrm{~N}$ & $\%$ & $\mathrm{~N}$ & $\%$ & $\mathrm{~N}$ & $\%$ \\
\hline Male & 11 & 69 & 29 & 41 & 6 & 55 & 15 & 40 \\
\hline Medication naïve & 7 & 43 & 21 & 30 & & & & \\
\hline LL homozygous & & & 38 & 54 & & & 13 & 34 \\
\hline $\begin{array}{l}\text { One or more current comorbid } \\
\text { disorder(s) }\end{array}$ & 7 & 44 & 24 & 34 & & & & \\
\hline $\begin{array}{l}\text { Eligible for functional magnetic } \\
\text { resonance imaging }\end{array}$ & 12 & 75 & 51 & 72 & 11 & 100 & 30 & 79 \\
\hline
\end{tabular}

striatal activity (30) (see the data supplement). Participants were asked to respond as quickly as possible to a target by pressing a button. Prior to display of this target, a cue (duration: 3.5-8.5 seconds) was given to indicate whether a reward could or could not be obtained. After each target response, the outcome was displayed. Participants could gain 1 euro in the reward condition and no money during the no-reward condition if they responded between $270 \mathrm{msec}$ and $500 \mathrm{msec}$ after target onset. This response window was individually adjusted (see the data supplement). The task consisted of a practice trial, after which the purpose of the task was again briefly summarized, followed by 50 trials in which reward and no-reward cues were randomly displayed. The experiment lasted 12 minutes, and a total of 12 euro could be gained. At the end of the experiment, the awarded money was shown on the screen and transferred to the participant's bank account. Reaction times in the reward and no-reward condition were the behavioral outcome measures.

\section{Behavioral Analysis}

Reward-related impulsivity. To assess the effects of ADHD status (ADHD patients relative to healthy comparison subjects) and NOS1 genotype (SS versus SL/LL) on reward-related impulsivity, analyses of variance (ANOVAs) were carried out using $\log \left(k_{10}\right)$, $\log \left(k_{30}\right), \log \left(k_{100}\right)$, and $\log \left(k_{\text {all }}\right)$ as dependent variables, and age and gender were incorporated as covariates. Cohen's d was calculated to identify effect size.

Monetary incentive delay task. A repeated-measures general linear model was performed to assess the effect of cue (reward/ no-reward) on response time. This general linear model was carried out with reaction time as the dependent variable and cue as the within-subject variable. The between-subject factors ADHD status and NOS1 exon 1f-VNTR genotype were added to the general linear model to identify group effects of cue-induced reaction times. Cohen's d was also calculated.

\section{fMRI Analysis}

After preprocessing (for details on fMRI acquisition and preprocessing, see the data supplement), first-level analyses were performed for each participant to estimate eight parameters of interest with a general linear model for the "cue," "target," "hit," and "miss" events in both the reward and no-reward conditions. These events were modeled as event-related regressors, with a zero duration, and convolved with the canonical hemodynamic response function in SPM5. Additionally, realignment parameters were included to account for movement-related variability, and time-derivatives were used, which resulted in 14 additional regressors of no interest. Data were high-pass filtered using a frequency cutoff of $1 / 128 \mathrm{~Hz}$.

To assess neural activity associated with reward anticipation, our contrast of interest concerned the reward and no-reward cue events. The contrast images for these events were submitted to a second-level random effect analysis, with the following full factorial $2 \times 2 \times 2$ design: ADHD status, NOS1 genotype, and cue (reward versus no-reward). Age and gender were included as covariates $(31,32)$. For the whole-brain analysis, the main effect of cue was tested using a threshold of $\mathrm{p}<0.05$ (family-wise error-corrected) and a cluster size threshold of 35 voxels. Because of our a priori hypothesis regarding the ventral striatum, the resulting suprathreshold ventral striatal region in the whole-brain analysis of the main effect of cue was defined as our region of interest. Defining this functional region for two groups with proven differential ventral striatal activity (such as ADHD patients and healthy comparison subjects $[13,14])$ bears the risk of bias if the two groups are not equal in size (for details see reference 33). To prevent any selection bias in our study (in which the patient group was bigger), we separately defined functional ventral striatal region for each diagnostic group and analyzed both groups to assess the effect of genotype. Cluster beta weights were extracted from these regions using the MarsBaR toolbox (34). To replicate previous studies on striatal hypoactivation in ADHD patients, a one-sided ANOVA was performed, with ADHD status as an independent variable and ventral striatal activity as a dependent variable. Pearson's correlations between ventral striatal activity and impulsivity were calculated. All statistical tests were two-sided, unless stated otherwise.

\section{Results}

Demographic characteristics of the study sample are presented in Table 1 . There were no significant differences between groups based on ADHD status or NOS1 exon 1f-VNTR 
TABLE 2. Behavioral Results of the Modified Monetary Incentive Delay Task for Adult ADHD Patients and Healthy Comparison Subjects ${ }^{\mathrm{a}}$

\begin{tabular}{|c|c|c|c|c|c|c|c|c|}
\hline \multirow[b]{4}{*}{ Variable } & \multicolumn{4}{|c|}{ ADHD Patients } & \multicolumn{4}{|c|}{ Comparison Subjects } \\
\hline & \multicolumn{4}{|c|}{ Genotype } & \multicolumn{4}{|c|}{ Genotype } \\
\hline & \multicolumn{2}{|c|}{$\begin{array}{l}\text { SS Allele Carrier } \\
\qquad(\mathrm{N}=12)\end{array}$} & \multicolumn{2}{|c|}{$\begin{array}{l}\text { SL/LL Allele Carrier } \\
\qquad(\mathrm{N}=51)\end{array}$} & \multicolumn{2}{|c|}{$\begin{array}{l}\text { SS Allele Carrier } \\
\qquad(\mathrm{N}=11)\end{array}$} & \multicolumn{2}{|c|}{$\begin{array}{l}\text { SL/LL Allele Carrier } \\
\qquad(\mathrm{N}=30)\end{array}$} \\
\hline & Mean & SD & Mean & SD & Mean & SD & Mean & SD \\
\hline Mean reaction time reward (msec) & 240.2 & 31.7 & 245.7 & 33.6 & 233.1 & 29.5 & 246.3 & 35.1 \\
\hline Mean reaction time no reward (msec) & 281.7 & 47.7 & 287.6 & 48.9 & 274.6 & 52.2 & 285.8 & 45.4 \\
\hline Hit rate reward & 0.40 & 0.03 & 0.40 & 0.05 & 0.41 & 0.05 & 0.39 & 0.05 \\
\hline Hit rate no reward & 0.37 & 0.06 & 0.35 & 0.07 & 0.35 & 0.07 & 0.35 & 0.06 \\
\hline
\end{tabular}

a Data for the short-short (SS), short-long (SL), and long-long (LL) genotypes of the NOS1 exon 1f-VNTR are shown.

FIGURE 1. Impulsivity Ratings on the Delay Discounting Task for Adult ADHD Patients and Healthy Comparison Subjects $^{\mathrm{a}}$

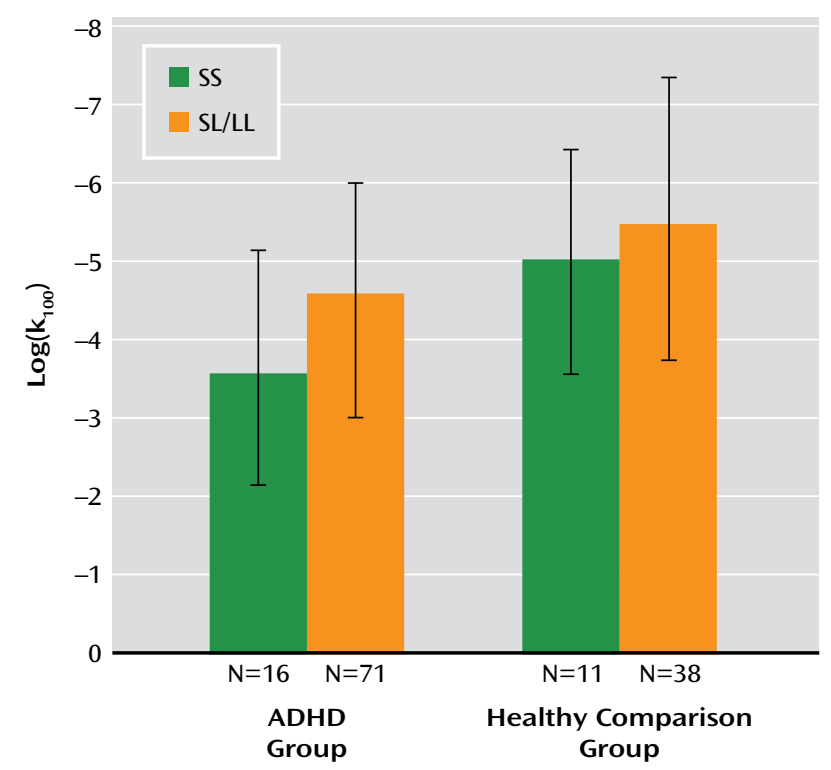

a Scores were higher in the ADHD group than in the healthy comparison group (less negative values [i.e., smaller bars] for $\log \left(k_{100}\right)$ represent higher impulsivity). Within the patient group, those with the homozygous short allele (SS) genotype had higher impulsivity scores than carriers of the short-long (SL) allele or long-long (LL) allele $(F=4.73, d f=1,85, p=0.03)$.

genotype with respect to gender, age, or IQ. ADHD patients and healthy comparison subjects showed the expected differences in self-reported ADHD symptoms $(\mathrm{p}<0.001)$ and an equal distribution of not otherwise specified exon lfVNTR genotype. Fifty-four patients fulfilled criteria for the combined ADHD subtype; 20 fulfilled criteria for the inattentive subtype; and 13 were characterized as hyperactive/ impulsive. Within the patient group, medication use was equally distributed over the genotype subgroups (SS, SL/ $\mathrm{LL}$ ), with no differences in disease severity between medicated and never-medicated patients. A similar distribution of characteristics was observed in the subsample of participants that underwent fMRI. In this subsample, $42 \%$ of ADHD patients and $24 \%$ of healthy comparison subjects were smokers, and smoking was equally distributed over the genotype groups (SS: $47 \%$; SL/LL: $32 \%$ ).

\section{Behavioral Results}

Reward-related impulsivity. ADHD patients showed higher levels of reward-related impulsivity than healthy comparison subjects on the delay discounting task $\left(\log \left(k_{\mathrm{all}}\right)\right.$ : $\mathrm{F}=7.15, \mathrm{df}=1,134, \mathrm{p}=0.008$ ). The strongest effect was found in the $k_{100}$ condition in which the largest amount of money (100 euro) was discounted $(\mathrm{p}<0.0001) . \log \left(k_{100}\right)$ was not significantly correlated with ADHD severity. In the ADHD group, patients with the SS genotype had higher reward-related impulsivity scores than those with SL/LL genotypes $(\mathrm{F}=4.73, \mathrm{df}=1,85, \mathrm{p}=0.03$, Cohen's $\mathrm{d}=0.60$ ) (Figure 1). In the comparison group, the effect of genotype did not reach significance. No interaction of diagnosis and genotype was observed. Within the ADHD group, impulsivity was not significantly correlated with ADHD severity (number of ADHD symptoms).

Modified monetary incentive delay task. A main effect of cue on reaction time was found for the monetary incentive delay task $(\mathrm{F}=165.54, \mathrm{df}=1,104, \mathrm{p}<0.0001)$. As expected, participants reacted faster in reward trials (mean response time: $243 \mathrm{msec}$ ) than in no-reward trials (mean response time: $284 \mathrm{msec}$ ) (Table 2). ADHD diagnosis, NOS1 genotype, or the interaction of both these factors did not affect cue-induced reaction time.

\section{Functional Imaging Results}

Brain regions activated in the "reward cue>no-reward cue" contrast are shown in Figure 2 (also see the data supplement). In the whole-brain analysis of the bilateral ventral striatum, the lateral prefrontal cortex, insula, left putamen, and left middle frontal gyrus were activated. Further analysis focused on bilateral ventral striatal activity.

Reward-related ventral striatal activity. Bilateral average cluster activity in the ventral striatum for both the patient and comparison groups is shown in Figure 2. ADHD patients had lower ventral striatal activity than healthy comparison subjects during reward anticipation $(\mathrm{F}=3.43, \mathrm{df}=1,102$, $\mathrm{p}=0.03)$, confirming findings in previous studies $(13,14)$. 
FIGURE 2. Ventral Striatal Activation in Response to Reward-Related Cue Events in Adult ADHD Patients and Healthy Comparison Subjects ${ }^{\mathrm{a}}$

A

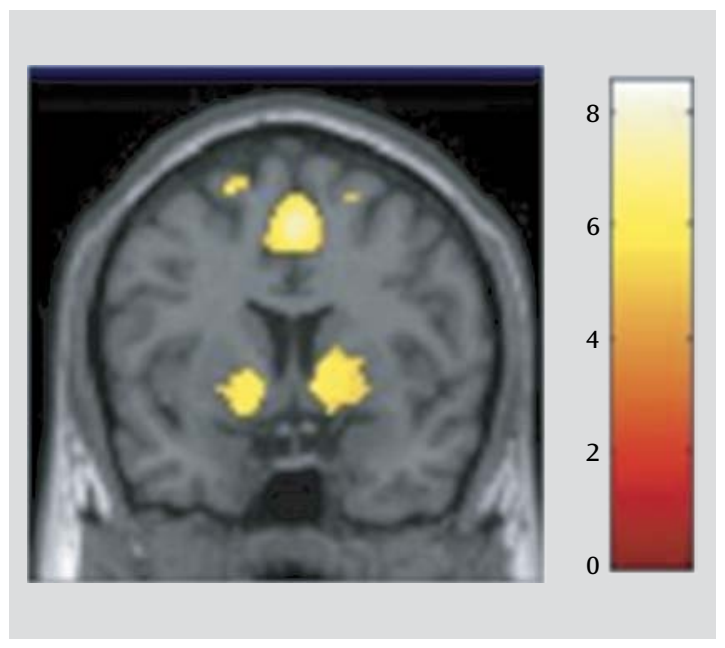

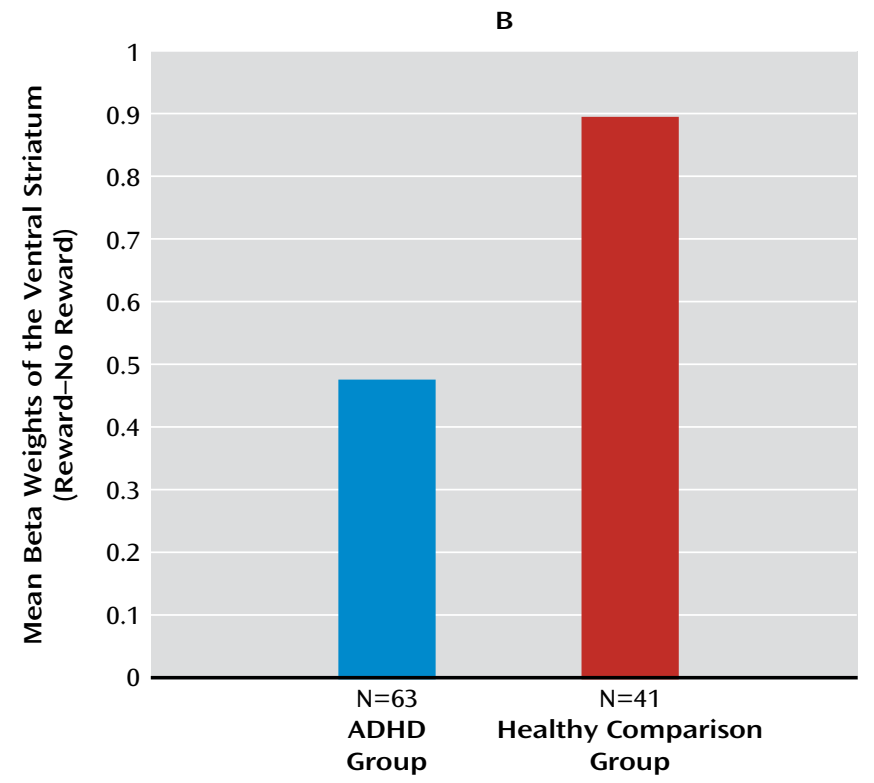

D

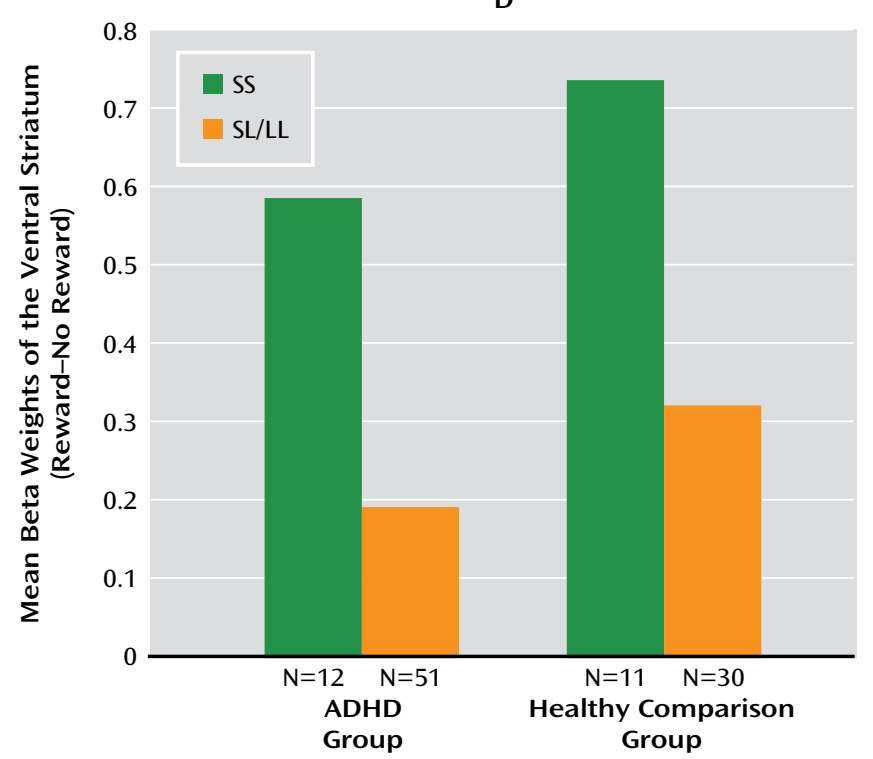

${ }^{a}$ The whole-brain analysis (A) ( $y=6, z=-4, p<0.05$ [family-wise error-corrected]) of main effect of reward anticipation ("reward cue $>$ no-reward cue" contrast) showing bilateral ventral striatal and frontal activity is depicted; the color bar represents T values. The mean beta weights (B) of the bilateral ventral striatum during the reward anticipation task for ADHD patients and healthy comparison subjects are shown. ADHD patients demonstrated hypoactivation of the ventral striatum relative to healthy comparison subjects. The bilateral ventral striatal functional regions of interest $(C)$ are displayed, as defined based on the activity patterns observed in both diagnostic groups (at $y=10, p=0.0005$, uncorrected) (ADHD group [blue]: cluster size: left, 315 voxels, right, 151 voxels; healthy comparison group [red]: cluster size: left, 990 voxels, right, 1,440 voxels). The mean beta weights of the bilateral ventral striatum during the reward anticipation task for the ADHD and healthy comparison groups stratified by NOS1 exon 1f-VNTR genotype (D) are depicted; results showed a genotype effect in both diagnostic groups, with the short-short genotype having higher striatal activation.

The functional region of interest that was defined based on striatal activity observed in the ADHD group (Figure 2) showed a significant effect of NOS1 genotype ( $\mathrm{F}=4.75$, $\mathrm{df}=1,61, \mathrm{p}=0.03$, Cohen's $\mathrm{d}=0.81$ ); this same effect was seen in analysis based on the functional region of interest defined by activity in healthy comparison subjects ( $\mathrm{F}=11.45$, $\mathrm{df}=1,39, \mathrm{p}=0.002$, Cohen's $\mathrm{d}=1.03$ ). For both definitions (in
ADHD patients and healthy comparison subjects), carriers of the SS genotype showed higher activity than SL/LL genotype carriers (Figure 2).

Ventral striatal activity did not differ between medicated and medication-naïve patients, nor was an effect of smoking observed among either patients or healthy comparison subjects. 
FIGURE 3. Correlation Between Ventral Striatal Activation and Impulsivity in Adult ADHD Patients and Healthy Comparison Subjects ${ }^{a}$

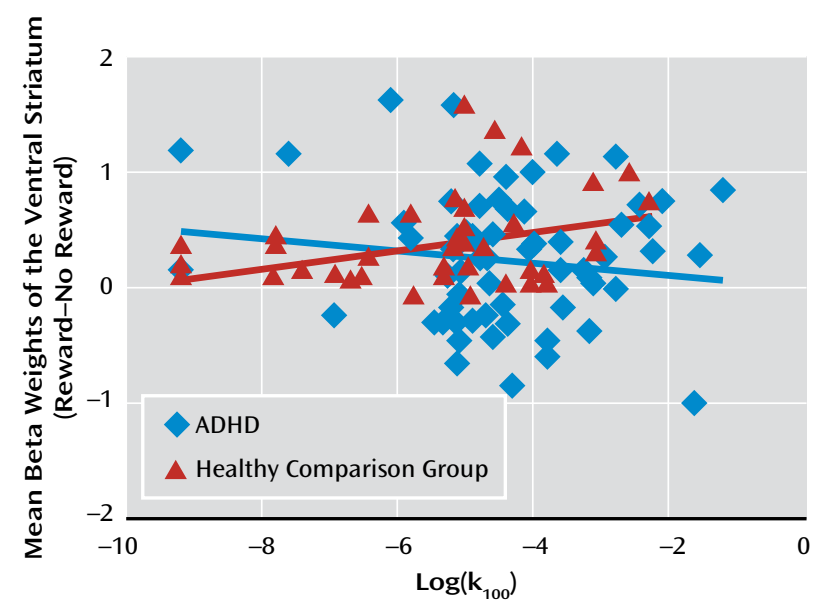

a The scatterplot depicts the correlation between reward-related impulsivity scores $\left(\log \left[k_{100}\right]\right)$ and ventral striatal activity.

Correlation between ventral striatal activity and impulsivity. The correlation between ventral striatal activity and impulsivity in healthy comparison subjects $(r=0.31$, $\mathrm{p}=0.04)$ was significantly different $(\mathrm{p}=0.04)$ from the correlation in ADHD patients (Figure 3).

\section{Discussion}

The NOS1 exon 1f-VNTR genotype influenced reward cue-related ventral striatal activity in the participants of this study, with the same direction of effect in both the ADHD and comparison groups. Genotype also modulated reward-related impulsivity levels in ADHD patients. The effect of the NOS1 genotype on reward-related impulsivity in the healthy comparison group was similar but did not reach statistical significance. A smaller subgroup with the short allele $(\mathrm{N}=11)$ may account for this failure to detect significance. The observed association of the NOS1 genotype with reward-related impulsivity in ADHD patients replicates earlier findings in patients with impulse-control disorders compared with healthy subjects $(21,22)$. Our results now extend the effect of the NOS1 genotype to ventral striatal activity, a critical component of the underlying neurological substrate of impulsivity (35).

The role of NOS1 in reward-related impulsivity, observed in the behavioral analysis of this study as well as in several psychiatric disorders and the general population $(3,15,22,36)$, suggests that the association of this gene with clinical phenotypes such as ADHD is mediated by its effect on this behavioral trait. Additionally, our finding that the genotype subgroup linked with higher reward-related impulsivity is associated with higher activity of the ventral striatum (which is consistent with previous research [35]) corroborates NOS1's role in impulsivity, since we now show that reward-cue-related impulsivity is positively correlated with ventral striatal activity in healthy subjects.
What appears discordant is the combination of increased ventral striatal activity in more impulsive healthy individuals with the reduced reward-related ventral striatal activity and no significant correlation with impulsivity in patients with ADHD, a disorder for which increased impulsivity is a hallmark $(12,13)$. For healthy individuals, our findings match those of an earlier study conducted by Hariri et al. (35), where impulsivity as measured by the delay discounting task was found to be positively correlated with ventral striatal activity. However, earlier studies with sample sizes smaller than that of our study reported a negative association in ADHD patients $(13,14)$.

Given the differences in findings for ventral striatal activity in ADHD patients and healthy individuals, one might have expected to observe a differential NOS1 genotype effect in the two groups or a gene-by-disorder interaction, as Durston et al. (37) found for the DAT1 gene. However, the finding of NOS1 genotype effects in the same direction in both groups shows that the NOS1 exon 1f-VNTR SS genotype related to ADHD does not contribute to ventral striatal hypoactivation in the disorder but acts on rewardrelated impulsivity. Thus, the ventral striatal hypoactivation in ADHD must be caused by something other than the NOS1 gene. One could consider altered baseline dopamine levels in the striatum in ADHD (38) as a possible explanation, since positive correlations between striatal dopamine and ventral striatal activity exist in healthy subjects (39). In addition, the influence of other ADHD candidate genes such as the dopamine transporter gene (DAT1/ SLC6A3) (40), which is also associated with altered dopaminergic synthesis-or perhaps an altered connectivity between the prefrontal cortex and striatum (41)—might play a role. Thus, one might hypothesize that the reduced ventral striatal activity is a compensatory mechanism to alleviate the effects of reduced prefrontal control.

Combined consideration of intermediate phenotypes, neurobiological mechanisms, and molecular genetic effects may therefore elucidate mechanisms contributing to the clinical symptoms of ADHD more completely than the analysis of any of these parameters in isolation. Consistent with these expectations, functional effects of the NOS1 exon 1f-VNTR genotype were more readily observed (i.e., higher effect size) in brain activity (Cohen's d range: 0.8-1.0) than at the behavioral level (Cohen's d range: 0.3$0.6)$, in accordance with the view that the former is more proximal to genes. Dissecting the clinical ADHD phenotype into relevant, measurable traits such as motivational deficits and assessing genetic effects on these traits on a neurobiological level are necessary steps to elucidate the biological mechanisms underlying the disorder.

Previously presented as a poster at the European Network for Hyperkinetic Disorders, May 26-28, 2010, Amsterdam; at the 16th Annual Meeting of the Organization for Human Brain Mapping, June 6-10, 2010, Barcelona, Spain; and at the Federation of European Neuroscience Societies Forum, July 3-7, 2010, Amsterdam. Received Oct. 8, 2010; revisions received Jan. 17, Feb. 16, and March 18, 2011; 
accepted March 28, 2011 (doi: 10.1176/appi.ajp.2011.10101446). From the Departments of Psychiatry, Human Genetics, and Cognitive Neuroscience, Radboud University Nijmegen Medical Centre, Donders Institute for Brain, Cognition and Behaviour, Nijmegen, the Netherlands; Radboud University Nijmegen Medical Center, Donders Institute for Brain, Cognition and Behaviour, Centre for Cognitive Neuroimaging, Nijmegen, the Netherlands; and the Karakter Child and Adolescent Psychiatric University Centre, Nijmegen, the Netherlands. Address correspondence to Dr. Franke (b.franke@antrg.umcn.nl).

In the past 3 years, Dr. Buitelaar has served as a consultant to/ member of advisory board of and/or speaker for Bristol-Myers Squibb, Eli Lilly, Janssen Cilag BV, Medice, Organon/Shering Plough, Servier, Shire, and UCB. All other authors report no financial relationships with commercial interests.

Funded in part by the Netherlands Brain Foundation (grant number, 15F07[2]27). Dr. Cools is supported by a Vidi grant from the Innovational Research Incentives Scheme of the Netherlands Organization for Scientific Research.

The authors thank Angelien Heister and Remco Makkinje for assistance with genotyping and Paul Gaalman for technical assistance with MRI scanning. The authors also thank all of the participants of this study.

\section{References}

1. Faraone S, Biederman J, Mick E: The age-dependent decline of attention deficit hyperactivity disorder: a meta-analysis of follow-up studies. Psychol Med 2006; 36:159-165

2. Burt S: Rethinking environmental contributions to child and adolescent psychopathology: a meta-analysis of shared environmental influences. Psychol Bull 2009; 135:608-637

3. Franke B, Neale B, Faraone S: Genome-wide association studies in ADHD. Hum Genet 2009; 126:13-50

4. Gizer I, Ficks C, Waldman I: Candidate gene studies of ADHD: a meta-analytic review. Hum Genet 2009; 126:51-90

5. Sonuga-Barke $\mathrm{E}$ : The dual pathway model of $\mathrm{AD} / \mathrm{HD}$ : an elaboration of neuro-developmental characteristics. Neurosci Biobehav Rev 2003; 27:593-604

6. Luman M, Oosterlaan J, Sergeant J: The impact of reinforcement contingencies on AD/HD: a review and theoretical appraisal. Clin Psychol Rev 2005; 25:183-213

7. Paloyelis Y, Asherson P, Kuntsi J: Are ADHD symptoms associated with delay aversion or choice impulsivity? a general population study. J Am Acad Child Adolesc Psychiatry 2009; 48:837-846

8. Scheres A, Lee A, Sumiya M: Temporal reward discounting and ADHD: task and symptom specific effects. J Neural Transm 2008; 115:221-226

9. Toplak M, Jain U, Tannock R: Executive and motivational processes in adolescents with attention-deficit-hyperactivity disorder (ADHD). Behav Brain Funct 2005; 1:8

10. Ernst M, Kimes A, London E, Matochik J, Eldreth D, Tata S, Contoreggi C, Leff M, Bolla K: Neural substrates of decision making in adults with attention deficit hyperactivity disorder. Am J Psychiatry 2003; 160:1061-1070

11. Pothuizen H, Jongen-Rêlo A, Feldon J, Yee B: Double dissociation of the effects of selective nucleus accumbens core and shell lesions on impulsive-choice behaviour and salience learning in rats. Eur J Neurosci 2005; 22:2605-2616

12. McClure S, Laibson D, Loewenstein G, Cohen J: Separate neural systems value immediate and delayed monetary rewards. Science 2004; 306:503-507

13. Ströhle A, Stoy M, Wrase J, Schwarzer S, Schlagenhauf F, Huss M, Hein J, Nedderhut A, Neumann B, Gregor A, Juckel G, Knutson B, Lehmkuhl U, Bauer M, Heinz A: Reward anticipation and outcomes in adult males with attention-deficit/hyperactivity disorder. Neuroimage 2008; 39:966-972

14. Scheres A, Milham M, Knutson B, Castellanos F: Ventral striatal hyporesponsiveness during reward anticipation in attentiondeficit/hyperactivity disorder. Biol Psychiatry 2007; 61:720-724
15. Reif A, Jacob C, Rujescu D, Herterich S, Lang S, Gutknecht L, Baehne CG, Strobel A, Freitag CM, Giegling I, Romanos M, Hartmann A, Rösler M, Renner TJ, Fallgatter AJ, Retz W, Ehlis AC, Lesch KP: Influence of functional variant of neuronal nitric oxide synthase on impulsive behaviors in humans. Arch Gen Psychiatry 2009; 66:41-50

16. Kiss J, Vizi E: Nitric oxide: a novel link between synaptic and nonsynaptic transmission. Trends Neurosci 2001; 24:211-215

17. Chen J, Zacharek A, Li Y, Li A, Wang L, Katakowski M, Roberts C, Lu M, Chopp M: N-cadherin mediates nitric oxide-induced neurogenesis in young and retired breeder neurospheres. Neuroscience 2006; 140:377-388

18. Reif A: Is NOS1 a genetic link between RLS and ADHD? J Psychiatr Res 2010; 44:60-61

19. Nelson R, Demas G, Huang P, Fishman M, Dawson V, Dawson T, Snyder SH: Behavioural abnormalities in male mice lacking neuronal nitric oxide synthase. Nature 1995; 378:383-386

20. Wultsch T, Chourbaji S, Fritzen S, Kittel S, Grünblatt E, Gerlach M, Gutknecht L, Chizat F, Golfier G, Schmitt A, Gass P, Lesch $K P$, Reif A: Behavioural and expressional phenotyping of nitric oxide synthase-I knockdown animals. J Neural Transm Suppl 2007; 72:69-85

21. Reif A, Kiive E, Kurrikoff T, Paaver M, Herterich S, Konstabel K, Tulviste T, Lesch KP, Harro J: A functional NOS1 promoter polymorphism interacts with adverse environment on functional and dysfunctional impulsivity. Psychopharmacology (Berl) 2011; 214:239-248

22. Retz W, Reif A, Freitag C, Retz-Junginger P, Rösler M: Association of a functional variant of neuronal nitric oxide synthase gene with self-reported impulsiveness, venturesomeness and empathy in male offenders. J Neural Transm 2010; 117:321-324

23. Sánchez-Mora C, Ribasés M, Ramos-Quiroga J, Casas M, Bosch R, Boreatti-Hümmer A, Heine M, Jacob CP, Lesch KP, Fasmer OB, Knappskog PM, Kooij JJ, Kan C, Buitelaar JK, Mick E, Asherson P, Faraone SV, Franke B, Johansson S, Haavik J, Reif A, Bayés M, Cormand B: Meta-analysis of brain-derived neurotrophic factor pVal66Met in adult ADHD in four European populations. Am J Med Genet B Neuropsychiatr Genet 2010; 153:512-523

24. Kooij J, Francken M: Diagnostisch Interview voor ADHD (DIVA) bij volwassenen. the Hague, the Netherlands, DIVA Foundation, 2007

25. DuPaul G, Power T, Anastopoulos A: ADHD Rating Scale-IV: Checklists, Norms and Clinical Interpretation. New York, Guilford, 1998

26. Brody A: Functional brain imaging of tobacco use and dependence. J Psychiatr Res 2006; 40:404-418

27. Dom G, De Wilde B, Hulstijn W, van den Brink W, Sabbe B: Behavioural aspects of impulsivity in alcoholics with and without a cluster-B personality disorder. Alcohol Alcohol 2006; 41:412420

28. Mazur JE: An adjusting procedure for studying delayed reinforcement, in Quantitative Analyses of Behavior, vol 5: the Effect of Delay and of Intervening Events on Reinforcement Value. Edited by Mazur JE, Commons ML, Nevin JA, Rachlin H. Hillsdale, NJ, Erlbaum, 1986

29. Richards J, Zhang L, Mitchell S, de Wit H: Delay or probability discounting in a model of impulsive behavior: effect of alcohol. J Exp Anal Behav 1999; 71:121-143

30. Hermans E, Bos P, Ossewaarde L, Ramsey N, Fernández G, van Honk J: Effects of exogenous testosterone on the ventral striatal BOLD response during reward anticipation in healthy women. Neuroimage 2010; 52:277-283

31. Becker J: Gender differences in dopaminergic function in striatum and nucleus accumbens. Pharmacol Biochem Behav 1999; 64:803-812

32. Mell T, Wartenburger I, Marschner A, Villringer A, Reischies F, Heekeren $\mathrm{H}$ : Altered function of ventral striatum during re- 
ward-based decision making in old age. Front Hum Neurosci 2009; 3:34

33. Kriegeskorte N, Simmons WK, Bellgowan PS, Baker CI: Circular analysis in systems neuroscience: the dangers of double dipping. Nat Neurosci 2009; 12:535-540

34. Brett M, Anton J, Valabregue R, Poline J: Region of Interest Analysis Using an SPM Toolbox. Oak Brook, Illinois, Sendai Publishing Group, 2002

35. Hariri A, Brown S, Williamson D, Flory J, de Wit H, Manuck S: Preference for immediate over delayed rewards is associated with magnitude of ventral striatal activity. J Neurosci 2006; 26:13213-13217

36. Reif A, Herterich S, Strobel A, Ehlis A, Saur D, Jacob C, Wienker T, Töpner T, Fritzen S, Walter U, Schmitt A, Fallgatter AJ, Lesch KP: A neuronal nitric oxide synthase (NOS-I) haplotype associated with schizophrenia modifies prefrontal cortex function. Mol Psychiatry 2006; 11:286-300

37. Durston S, Fossella JA, Mulder MJ, Casey BJ, Ziermans TB, Vessaz $\mathrm{MN}$, van Engeland $\mathrm{H}$ : Dopamine transporter genotype conveys familial risk of attention-deficit/hyperactivity disorder through striatal activation. J Am Acad Child Adolesc Psychiatry 2008; 47:61-67
38. Spencer TJ, Biederman J, Madras BK, Faraone SV, Dougherty DD, Bonab AA, Fischman AJ: In vivo neuroreceptor imaging in attention-deficit/hyperactivity disorder: a focus on the dopamine transporter. Biol Psychiatry 2005; 57:1293-1300

39. Schott BH, Minuzzi L, Krebs RM, Elmenhorst D, Lang M, Winz $\mathrm{OH}$, Seidenbecher $\mathrm{Cl}$, Coenen HH, Heinze HJ, Zilles K, Düzel E, Bauer A: Mesolimbic functional magnetic resonance imaging activations during reward anticipation correlate with rewardrelated ventral striatal dopamine release. J Neurosci 2008; 28:14311-14319

40. Hahn T, Heinzel S, Dresler T, Plichta MM, Renner TJ, Markulin F, Jakob PM, Lesch KP, Fallgatter AJ: Association between rewardrelated activation in the ventral striatum and trait reward sensitivity is moderated by dopamine transporter genotype. Hum Brain Mapp (E-pub ahead of print, September 15, 2010)

41. Konrad A, Dielentheis TF, El Masri D, Bayerl M, Fehr C, Gesierich T, Vucurevic G, Stoeter P, Winterer G: Disturbed structural connectivity is related to inattention and impulsivity in adult attention deficit hyperactivity disorder. Eur J Neurosci 2010; 31:912-919 